\title{
REPORT 991
}

\section{THE APPLICATION OF THE STATISTICAL THEORY OF EXTREME VALUES TO GUST-LOAD PROBLEMS}

\author{
By Harry Press
}

\section{SUMMARY}

An analysis is presented which indicates that the statistical theory of extreme values is applicable to the problems of predicting the frequency of encountering the larger gust loads and gust velocities for both specific test conditions as well as commercial transport operations. The extreme-talue theory prorides an analytic form for the distributions of maximum values of gust load and velocity. Mlethods of fitting the distribution are given along with a method of estimating the reliability of the predictions.

The theory of extreme zalues is applied to atailable load data from commercial transport operations. The results indicate that the estimates of the frequency of encountering the larger loads are more consistent with the data and more reliable than those obtained in previous analyses.

\section{INTRODUCTION}

In the investigation of the loads imposed on airplanes due to gusty air, flight measurements of loads and gust relocities have been used to obtain estimates of the expected load experience under various operating conditions. For the problem of designing airplanes for ultimate static failure, the larger gust velocities are of particular interest, as they are likely to cause structural damage. Because the Iarger gust velocities are infrequent, measurements arailable from limited samples of data will generally not extend to the larger and critical ralues of gust relocity and load. Consequently, an important problem in these investigations is the development of techniques for estimating the probabilities of encountering these larger values.

Previous analyses of data obtained from gust-load investigations have utilized the statistical approach and considered the measurements obtained as random samples for the conditions studied. In the analysis of records obtained from investigations with $V$-G recorders (references 1,2 , and 3 ), the largest values of the significant rariables have been selected on some convenient and consistent basis. Frequency distributions of the largest. ralues have been represented by fitted Pearson type III probability curves. Experience with the use of curves of this type has indicated, howerer, that the estimates of the probabilities of exceeding the larger and extrapolated values of the rariables cannot be considered reliable. In some cases, there has appeared evidence that the estimated probabilities of exceeding the larger values were too low. A further difficulty, resulting from the

arbitrary selection of the curve t5pe, has been the inability to derive satisfactory methods of measuring the reliability of extrapolated predictions.

Recent developments in the statistical theory of extreme values (references 4 to 10 ) have indicated a somewhat more rational approach to the problem of predicting the probability of occurrence of the extreme values. In some cases, this new approach provides a more satisfactory solution to the statistical problem of the determination of the form of the distributions of largest values. In addition, methods are arailable for obtaining measures of the reliability of predicted values. The present report summarizes some of these findings, indicates the method of application, and eraluates their applicability to certain gust-load problems.

\section{SYMBOLS.}

$m$

$N$

$n$

$U_{e}$

$U_{t}$

$\Delta n$

r

$V_{L}$

$T_{0}$

$x$

$x_{m}$

$x_{n-1}$

$x_{x}$

$w(x)$

$W^{\top}(x)$ number of observation in order from smallest to largest

number of observations from which a maximum is selected

total number of observations of maximum values effective gust relocity, feet per second true gust velocity, feet per second normal-acceleration increment, $g$ units airspeed, miles per hour design level cruising speed, miles per hour airspeed at which maximum acceleration increment occurs on $V$-G record random variable $m$ th ralue from lowest of $n$ values of $x$ second largest ralue of $n$ values of $x$ largest value of $n$ values of $x$ probability density function of $x$. cumulative probability distribution of $x$ defined

$F(x)=1-$ W $(x)$

$$
\text { by } \int_{-\infty}^{x} w(x) d x
$$

$w^{*}(x) \quad$ probability density function of maximum values of $x$

$W *(x) \quad$ cumulative probability distribution of maximum values of $x$

$F^{*}(x)=1-W^{*}(x)$

$T(x) \quad$ recurrence period of $x$, average number of observations required to equal or exceed given values of $x$ 
$y \quad$ reduced variable defined by $y=\alpha(x-u)$

$y_{m} \quad m$ th value of $n$ observations of $y$

$v^{*}(y) \quad$ probability distribution of reduced variable $y$

$V^{*}(y) \quad$ cumulative probability distribution of reduced variable $y$

$(\sigma \sqrt{n})_{m} \quad$ reduced standard error of $m$ th of $n$ observations defined by equation (13)

$s \quad$ sample estimate of $\sigma$ given by $\sqrt{\frac{\sqrt{(x-\bar{x})^{2}}}{n-1}}$

$S_{n}=\frac{1.14}{\alpha}$

$S_{n-1}=\frac{0.754}{\alpha\left(1-\frac{2}{n}\right)}$

$S_{m} \quad$ standard deviation of $m$ th value of $n$ observations

of $x \quad\left(\frac{(\sigma \sqrt{n})_{m}}{\alpha \sqrt{n}}\right)$

$u \quad$ statistical parameter of distribution of extreme values defined by equation (5)

$\alpha \quad$ statistical parameter of distribution of extreme values $\left(\frac{w(u)}{1-\Pi^{\top}(u)}\right)$

$\mu \quad$ universe mean value of random variable given by

$$
\int_{-\infty}^{\infty} x w(x) d x
$$

$\sigma \quad$ standard deviation of random variable defined by

$\left[\int_{-\infty}^{\infty}(x-\mu)^{2} w(x) d x\right]^{1 / 2}$

$\tau \quad$ average number of hours per $V$-G record

Subscripts:

$L L F \quad$ design limit load factor

$\max \quad$ maximum value of random variable for specified sample

$A$ bar is used over symbols to indicate the mean value of $n$ values of a random variable given by $\frac{\Sigma x}{n}$. A tilde $\sim$ is used above a statistical parameter to designate the true universe value.

\section{BASIC STATISTICAL CONSIDERATIONS}

In the application of statistical methods to gust-load problems, the maximum values of such gust variables as normal acceleration and effective gust velocity obtained under given conditions have frequently been selected for analysis. The frequency distribution of the maximum values obtained from successive samples has been utilized to obtain estimates of the probability of encountering extreme values. The problem of obtaining estimates of the probability of encountering the extreme values would be considerably simplified by the a priori determination of the underlying distribution of the maximum values of the variables. The knowledge of the underlying distribution should also greatly increase the accuracy and reliability of the required estimates.
Consideration of recent, work in the theory of extreme values has indicated that this theory would appear applicable to gust-load problems if the initial distribution of the variables satisfied certain requirements. The theory of extreme values indicates that for certain initial distributions a limiting form exists for the distributions of the maximum values. In particular, for initial distributions of the exponential type, the limiting form of the distribution of maximum values has been found (reference 5) to be a simple annlytic function. This case appears applicable to certain phases of gust statistics and will, therefore, be discussed in some detuil.

Consider a random variable $x$ having a probability distribution $w(x)$. The variable $x$ is assumed to have no uppor limit; that is, $w(x)$ is greater than zero for all increasing values of $x$. The cumulative probability distribution from below is then given by

$$
\Pi^{\prime}(x)=\int_{-\infty}^{x} w(x) d x
$$

and indicates the probability that a measurement is less than a given value of $x$. Similarly, the cumulative probubility distribution from above is defined by

$$
F(x)=\int_{x}^{\infty} w(x) d x
$$

and indicates the probability that a measurement is greater than the given value of $x$. The probability that a value $x$ is a maximum of $N$ observations may be obtained from the product probabilities and is given by

$$
W^{*}(x)=[W(x)]^{N}=\left[\int_{-\infty}^{x} w(x) d x\right]^{N}
$$

A simple analytic expression for $\mathrm{I}^{*}(x)$ is of course not possible, in general, inasmuch as it depends on the form of the initial distribution. If $N$ is very large, asymptotic solutions are possible for certain forms of the initial distribution $w(x)$. In particular, if $w(x)$ is of the exponetial form, it hins been shown (reference 5 ) that

$$
\Pi^{*}(x)=e^{-\varepsilon^{-\alpha(x-u)}}
$$

where $u$ is the expected largest value defined by

$$
W(u)=1-\frac{1}{N}
$$

and $\alpha$ is defined by

$$
\alpha=\frac{w(u)}{1-W^{\prime}(u)}
$$

The significance of the parameter $\alpha$ is indicated subsequently.

The distribution of the maximum values of $x$ may be obtained from equation (4) and is given by

$$
w^{*}(x)=\frac{d}{d x} W^{*}(x)=\alpha e^{-\alpha(x-u)-e^{-\alpha(x-u)}}
$$


The distribution of maximum values given by equation (7) is a two-parameter family of curres with parameters $u$ and $\alpha$. The distribution has positive skerness with a modal value less than the mean.

In order to simplify the foregoing results, the linear transformation defined by

$$
y=\alpha(x-u)
$$

is utilized to transform equation ( 7 ) to a simpler form. From equations (4), (7), and (8), the following equations are obtained:

$$
\Gamma^{* *}(y)=\Pi^{*}(x)=e^{-e^{-v}}
$$

and

$$
v^{*}(y)=e^{-y-a^{-y}}
$$

The distributions of equations (9) and (10) are shown in figures 1 and 2, respectively. It is noted from figure 2 that the distribution of equation (10) has one and only one maximum at $y=0$ and, therefore, the mode of the distribution of largest values given by equation (7) must be equal to $u$.

For a known distribution, the rate of increase of the maximum value of a variable with increasing sample size is specified inasmuch as the arerage number of observations required in order to equal or exceed given ralues of the variable may be determined. If a function $T(x)$ is defined as the average number of maximum values required in order to equal or exceed given values of $x$, analysis has indicated

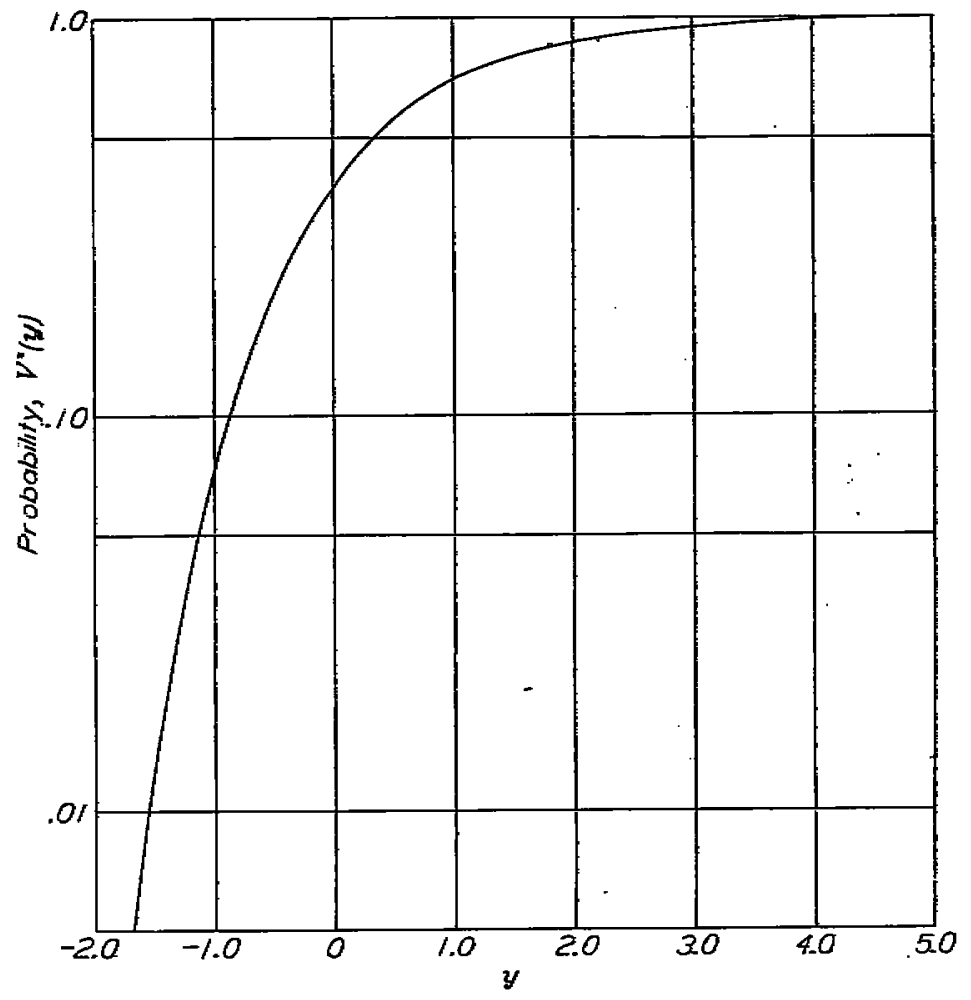

FIGCRE 1-Cumulatire probabilfty distribution function

$$
I^{* *}(y)=\int_{-\infty}^{y} e^{-y-e^{-y}} d y=e^{-e^{-y}} \text { (equation 9). }
$$

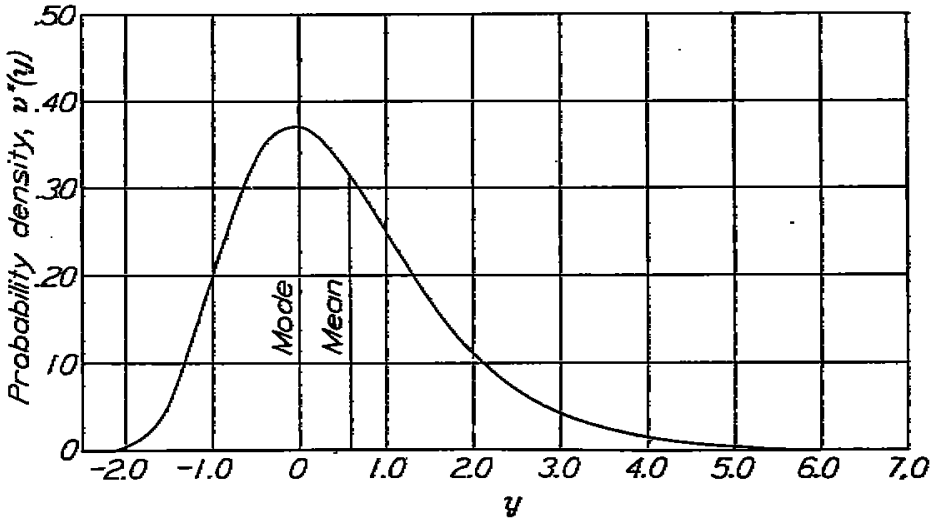

FIG TRE 2-Probebility density function $p^{*}(y)=\varepsilon^{-y-\epsilon^{-y}}$ (equatiou 10).

that the value of $x$ exceeded in $T(x)$ observations will increase as a linear function of $\log _{e} T(x)$. The results obtained in reference 6 , page 178 , indicate that for large values of $x$

$$
\log _{\triangleleft} T(x) \approx \alpha(x-u)
$$

or

$$
\log _{10} T(x) \approx 0.4343 \alpha(x-u)
$$

For ralues of $x$ such that $T(x)>10$, this relationship is a sufficiently close approximation for most purposes. This result indicates that for large values of $x$ the arerage number of samples necessary to equal or exceed given values of $x$ converges toward a simple exponential function of $x$. From equation (11), it is also apparent that the derirative of $x$ with respect to the $\log _{a} T(x)$ is a constant and is giren by $1 / \alpha$. The parameter $\alpha$, thereby, specifies the rate of increase of the maximum value of the rariable with increasing sample size.

Equation (7) gives the probability distribution function of maximum values obtained from samples of a random variable with a specified type of initial distribution. A sample of maximum values may then be used to obtain estimates of parameters of the population of maximum values. It would be expected, however, that successive samples from the same population will indicate some differences in parameter estimates due to chance, the magnit ude of the differences depending on the sample size. In practice, the parameters of the population are seldom known and sample estimates must be used. Methods have been developed for measuring the reliability of sample estimates by indicating a range within which, for a giren probability level, the population value can be expected to lie. (See, for example, reference 11.)

A simple and rapid method of indicating the reliability of sample estimates of the extreme-ralue distribution function called "control curves" has been derived by Gumbel in references 8 and 9 . These control curres provide a measure, for a given probability level, of the range within which the true population value may be expected. Kimball in reference 10 has suggested a more precise, though considerably 
more complex, method of obtaining confidence limits for the distribution of extreme values. In the interest of simplicity, the present discussion will be restricted to the method given by Gumbel.

The method of obtaining control curves derived by Gumbel depends essentially on the determination of control intervals at discrete points along the distribution by the utilization of the properties of the distribution of the $m \mathrm{th}$, values. Within the range $0.1<W^{*}(x)<0.9$, the distribution of the $m$ th values of a continuous variable having moderate skew distribution and possessing a mode is asymptotically normal around the most probable $m$ th value (reference 5) with a standard error $(\sigma \sqrt{n})_{m}$ given by:

$$
(\sigma \sqrt{n})_{m}=\frac{\sqrt{\left[\mathbb{W}^{*}\left(x_{m}\right)\right]\left[1-\mathrm{H}^{*}\left(x_{m}\right)\right]}}{w^{*}\left(x_{m}\right)}
$$

The function $(\sigma \sqrt{n})_{m}$ is hereinafter called the "reduced standard error" and is shown as a function of $F^{*}\left(x_{m}\right)$ and $y$ in figure 3. A horizontal interval around the truc mtlk value given by

$$
\tilde{x}_{m}-S_{m}<\tilde{x}_{m}<\tilde{x}_{m}+S_{m}
$$

where $S_{m}$ is defined by

$$
S_{m}=\frac{(\sigma \sqrt{n})_{m}}{\alpha \sqrt{n}}
$$

gives a probability of about 0.68 that the $m$ th value in a sample of $n$ observed maximum values will lie in the enclosed interval. Similarly, the interval $\tilde{x}_{n} \pm 2 S_{m}$ has a probability of about 0.95 of enclosing the $m$ th value from a sample of $n$ observed maximum values.

In order to obtain a control interval at the larger values, a fundamental property of the distribution of maximum values may be utilized. The most probable largest value of $n$ maximum values has been shown (reference 4) to lave a distribution of the same form as the distribution of the $n$. maximum values with the origin shifted to the right by a

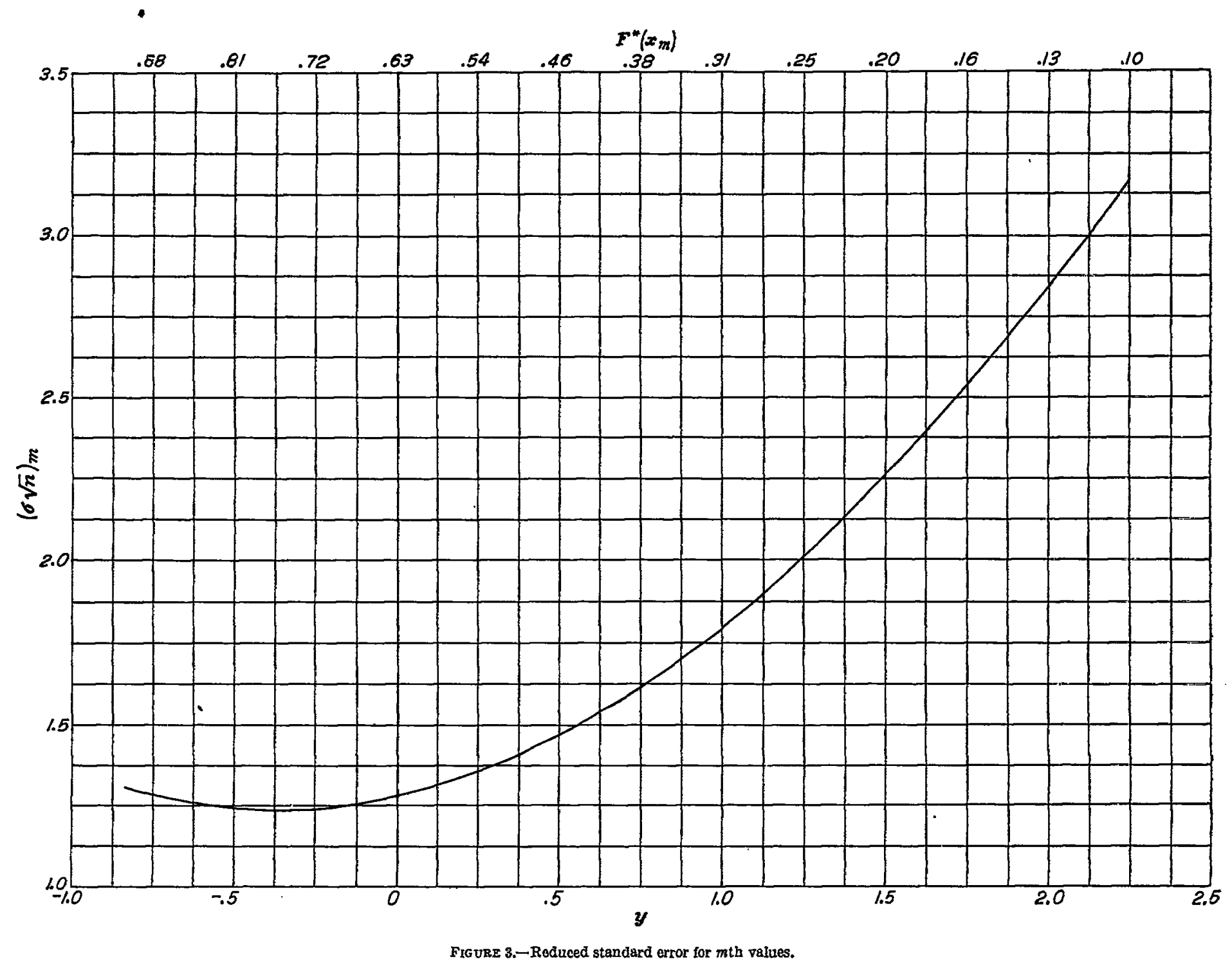


distance equal to the $\log _{e} n$ and with the standard deviation unchanged. Consideration of the probability distributions of extreme values indicates that an interval around the most probable largest value having a probability of about 0.68 is given by

$$
\tilde{x}_{x}-S_{n}<\tilde{x}_{n}<\tilde{x}_{n}+S_{n}
$$

where

$$
S_{n}=\frac{1.14}{\alpha}
$$

Similarly, for a probability level of 0.95 , the control interval around the most probable largest value is given by $\widetilde{x}_{n} \pm \frac{2.97}{\alpha}$. Since the control interval around the most probable largest value does not depend upon the number of observations $n$, Gumbel has suggested that a control interval of equal width may be extended along the extrapolated portion of the curre.

In order to fill the gap in the control intervals for those values not near the median nor the extreme value, the following equation was obtained by Gumbel in reference 9 , page 11, for the control interval around the most probable penultimate value:

$$
\tilde{x}_{n-1}-S_{n-1}<\tilde{x}_{n-1}<\tilde{x}_{n-1}+S_{n-1}
$$

where $S_{n-1}$ is an approximation given by

$$
S_{n-1}=\frac{0.754}{\alpha\left(1-\frac{2}{n}\right)}
$$

The control curves defined by equations (18) and (19) have a probability level of 0.68 . For a probability level of 0.95 , the numerator of equation (19) becomes 1.73 instead of the value of 0.754 .

Inasmuch as the foregoing method allows the determination of control intervals around the sample distribution at discrete points along the distribution, fairing a smooth curre through the points is necessary to obtain a continuous control curve.

Closely related to the control intervals is the problem of the significance of observed differences between the distributions of samples of data. In the analysis of gust-load data, it is frequently required to determine whether the differences in probabilities of occurrence of extreme or critical values between two samples are significant. The following procedure based on the control curres presented herein is suggested as a test of significant differences:

(1) Obtain the control intervals with a probability of 0.95 for the two samples at the ralue of $x$ at which the comparison is to be made.

(2) If each of the control interrals does not enclose the probability value obtained from the other sample, the observed differences may be considered significant.
(3) If either or both control intervals do enclose the value obtained from the other sample, the differences cannot be considered real and may be attributed to sampling fluctuations.

Although the foregoing test for significant differences cannot be considered rigorous, it would appear to be a reasonable test designed in accordance with the levels of significance commonly used in statistical tests.

\section{Determination of Parameters}

The preceding analysis has presented a basic distribution for fitting distributions of maximum values provided that the initial distribution is of the simple exponential type. The process of fitting the distribution of extreme values to observed frequency distributions requires the estimation of the parameters $u$ and $\alpha$ from the sample data. Several methods are available for the determination of the parameters. The accuracy with which the parameters can be estimated depends upon the number and accuracy of observations available. In practice, a minimum of about twenty-five observations has been found generally to be required.

For large samples of data, $n>75$, the relations obtained for the parameters from the method of moments have yielded satisfactory results. The method of moments gives the following asymptotic relations for the required parameters (reference 5):

$$
\begin{aligned}
& u=\mu-\frac{e}{\alpha} \\
& \frac{1}{\alpha}=\frac{\sqrt{6} \sigma}{\pi}
\end{aligned}
$$

where $c$ is Euler's number and equals 0.5772 and $\mu$ and $\sigma$ are the mean and standard deviation, respectively, of the universe distribution of maximum values. If equations (20) and (21) are assumed to be true when the parameter values are replaced by their respective sample estimates where $\mu$ is estimated by $\bar{x}$ and $\sigma$ is estimated by $s$, the following equations are obtained:

$$
u=\bar{x}-\frac{c}{\alpha}
$$

and

$$
\frac{1}{\alpha}=\frac{\sqrt{6} s}{\pi}
$$

For samples of data, estimates of the values of $u$ and $\alpha$ may be determined from equations (22) and (23). The values of the parameters obtained for $u$ and $\alpha$ are then utilized with the transformation equation (8). For given values of $x$, equation (8) gives "equivalent ralues" of $y$ "ralues of $y$ having the same probability of being exceeded as the given value of $x$ ). The probabilities that a value of $y$ and the associated value of $x$ will be exceeded may then be obtained simply from table $\mathrm{I}$. 
For smaller samples, more precise methods of estimating the parameters are generally required in order to obtain satisfactory representation of the observed cumulative frequency distribution. One such method involves the utilization of the transformation equation (8). Observed values of $x$ may be transformed to values of $y$ by equating the observed points of the cumulative frequency distribution with the distribution of $F^{*}(y)$. The principle of least squares may then be applied to arrive at estimates of the required parameters in equation (8). The two normal equations that are obtained from the principle of least squares are

$$
\begin{gathered}
\frac{\Sigma x}{n}=u+\frac{\Sigma y}{n \alpha} \\
\frac{\Sigma x y}{n}=u \frac{\Sigma y}{n}+\frac{\Sigma y^{2}}{n \alpha}
\end{gathered}
$$

and may be solved simultaneously. Gumbel (reference 9) has suggested a simplification of the calculation by obtaining from equations (24) and (25) the following equations, in terms of the sample estimates:

$$
\begin{aligned}
& \bar{x}=u+\frac{\bar{y}}{\alpha} \\
& \frac{1}{\alpha^{2}}=\frac{\left(s_{x}\right)^{2}}{\left(s_{y}\right)^{2}} .
\end{aligned}
$$

For very large samples, $\bar{y}$ approaches 0.5772 , Euler's number, and $\left(s_{y}\right)^{2}$ approaches $\bar{\pi}^{2} / 6$; these values are the same as those obtained from the method of moments.

In the analysis of small samples, the procedure to be followed in determining equivalent values of $y$ for each of the observed values of $x$ requires the enumeration of the observations in order of size from smallest to largest. For given values of $x$, the ratio of $\frac{n-m+1}{n}$ gives the proportion of observations equal to or greater than the given value. This ratio, sometimes called the recurrence ratio, gives a measure of the probability $F^{*}(x)$ that the given value of $x$ will be equaled or exceeded. Table I may be used simply for the conversion of observed recurrence ratios as observed estimates of $F^{*}(y)$. One observation is lost by this procedure because the recurrence ratio for the smallest observation is equal to 1 and an equivalent value of $y$ cannot be determined. The loss of the smallest value is of little consequence because the principal interest lies with the other end of the distribution.

The values of the parameters obtained by the use of equations (26) and (27) can then be used with the transformation equation (8) to obtain the probability distribution in the same manner as previously indicated for the case of large samples.
In order to illustrate the application of the foregoing methods to gust-load data, two exumples are sclected and the methods of calculation indicated for the case of both the large and small samples.

Example 1.-Gust-velocity measurements were available for 485 traverses of thunderstorms from the 1946 operations of the $\mathrm{U}$. S. Weather Burcau Thunderstorm Project. The frequency distribution of the maximum values of gust velocity per traverso is shown in table II. The relations obtained from the method of moments, equations (22) and (23), are used to determine the values of the parameters $u$ and $\alpha$ as indicated in the tuble. By utilizing the values of the parameters, the transformation equation given by

$$
y=\frac{U_{e}-12.8370}{4.8263}
$$

is obtained. For given values of $U_{\varepsilon}$, transformed or cquiralent values of $y$ are obtained. Table II also inclicates the equivalent values of $y$ for given values of $I_{6}$ from 2 to 48 feet per second. The associated probabilities of excecling the indicated values of $L_{\omega}$, oblained from table $I$, are also shown. Figure 4 illustrates the fitted extreme-value probnbility distribution along with the cumulative-data points.

Control intervals for 68-percent and 95-percent probability levels were determined by means of the rolations given by equations (13) to (19) and the results obtained are shown in table III. The control intervals were then used to obtain the faired control curves shown in figure 4.

Example 2.-Records obtained during recent operations of a modern transport airplane were sclected for the second example. Twenty-six V-G records, each representing roughly 250 hours of flight operation, were available for a particular airline operator and route. The twenty-six maximum accelerations obtuined from the records are given in table IV. The necessary operations in the craluation of the parameters $u$ and $\alpha$ are also indicaled in the table. The values of the parameters obtained give the following relation for the transformation equation:

$$
y=\frac{\Delta n-0.8674}{0.2874}
$$

The transformation equation and table I were then used to obtain the probabilities of exceeding given values of $\Delta n$, and the results obtained are shown in the table. The probnbilities of exceeding given values of $\Delta n$ along with the cumulative data points are shown in figure 5.

The relations for the control intervals given by equations (13) to (19) were used to obtain the 68-percent and 95-percent control intervals for several values of $F^{*}(\Delta n)$ and the results obtained are shown in table $V$. The continuous control curves obtained by fairing are shown in figure 5 . 
THE APPLICATION OF THE STATISTICAL THEORY OF EXTREME VALUES TO GUST-LOAD PROBLEMS

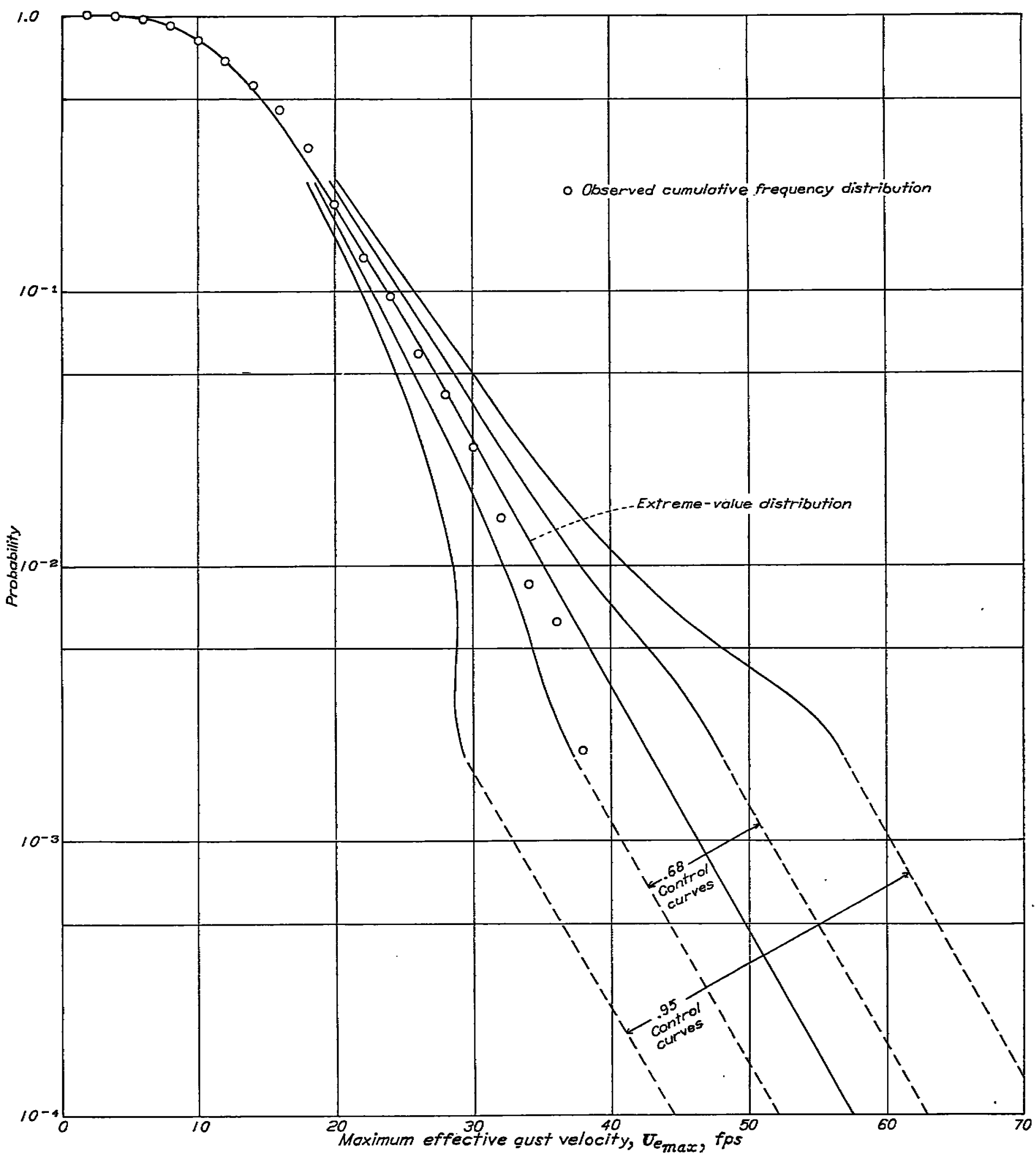

Fic URa 4. - Probability that the maximum ralue of $U_{\epsilon}$ per traverse will exceed indicated ralue; 1946 $\mathrm{V}$. S. Weather Bureau Thundexstorm Project dats; example 1. 


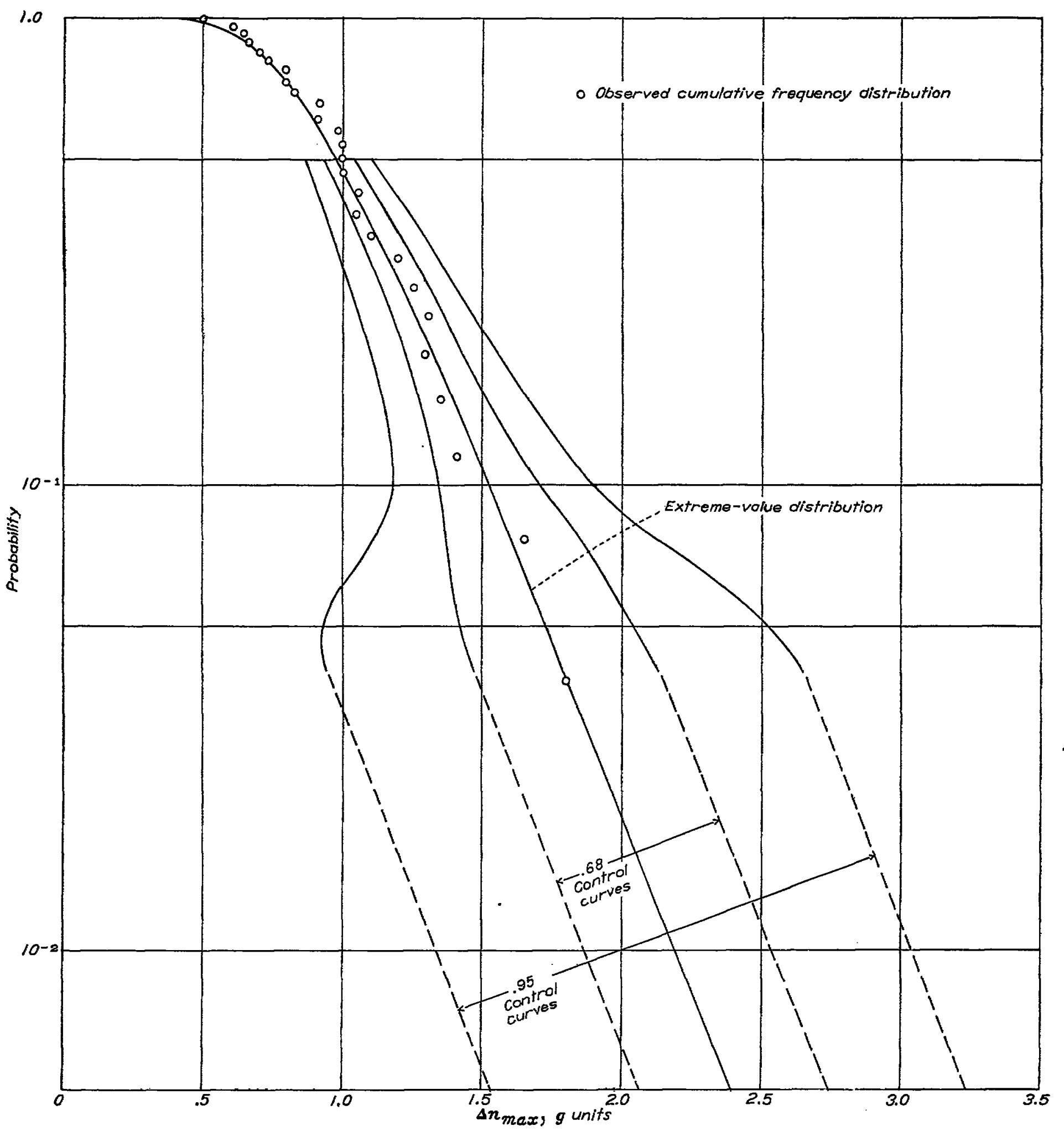

FlGORE 5--Probability that the maximum value of acceleration increment per record will exceed indicated yalue; $V-Q$ data; cxnmple 2. 


\section{APPLICATION AND RESULTS}

The fundamental variables generally considered in gustload investigations include: the effective gust relocity $U_{e_{2}}$ the normal-acceleration increment $\Delta n$, the true gust velocity $U_{b}$, and airspeed $T$. In order to determine whether the distribution of extreme values is applicable to distributions of maximum values, consideration of the initial distributions of the variables is required. The arailable data on the distribution of the aforementioned rariables have consequently been examined.

Distributions of effective gust velocity obtained under a variety of operating conditions have been reported in reference 12. At the present time, however, the only extensive distributions of gust variables have been obtained in cloud flight from the operations of the U. S. Weather Bureau Thunderstorm Project (reference 13) and the NACA airplane investigations of reference 14 . The relative frequency distributions of $U_{e}, \Delta n$, and $U_{t}$ obtained from these investigations are presented in figures 6,7 , and 8 , respectively.

Extreme-ralue distributions were fitted to distributions of maximum values of $\Delta n$ a vailable from $r-G$ records, in order to compare the results obtained by the use of the extremevalue theory with those obtained in previous analysis of $V^{r}$-G data. Thirteen sets of records were available for analysis although six of these had only II to 19 records each. The remaining seren sets had more than 25 records with

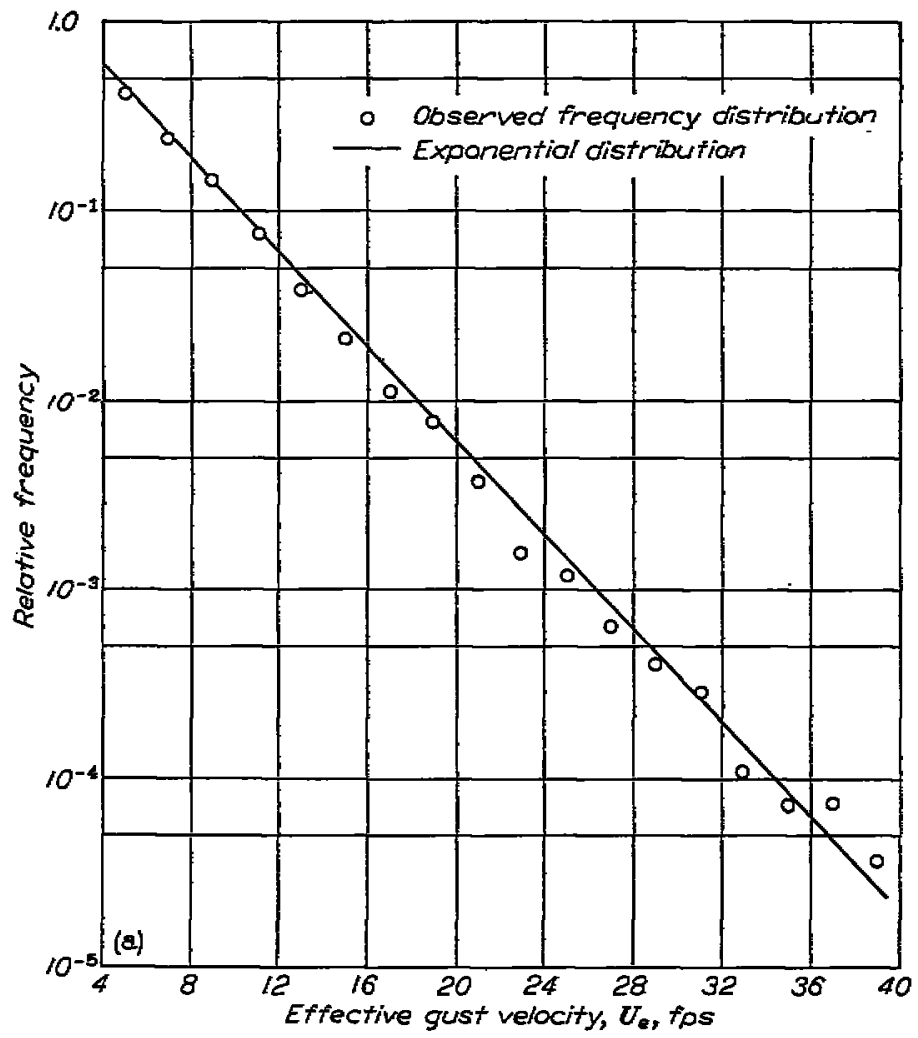

(a) 2946 Thunderstorm Project data. Total number of observations, 27,486. FIG tre 6.-Distribution of effective gust relocity $\tau_{\text {s. }}$. one exception, for which only 24 records were available. One of these seven sets was discarded because during one flight a hurricane was encountered which resulted in an unusually large acceleration. This unusual occurrence appears to preclude a simple statistical treatment of the data for this set.

Extreme-ralue distributions were fitted to the six sets of acceleration increments in accordance with the methods previously outlined. The average miles of flight required to exceed given values of acceleration increment were determined by using the relation

$$
\text { Mileage }=\frac{0.8 T_{L}}{P} \tau
$$

where $P$ is the probability that a given maximum value for a record will exceed the giren value, $\tau$ is the average flight hours per record, and the airplane is assumed to fly at an arerage speed of $0.8 \Gamma_{L}$.

As a basis of evaluation of the results obtained, the total miles of flight represented by each set of data are compared with the estimated number of miles (obtained from the probability curves) required to exceed the largest value of acceleration increment actually measured in each set.

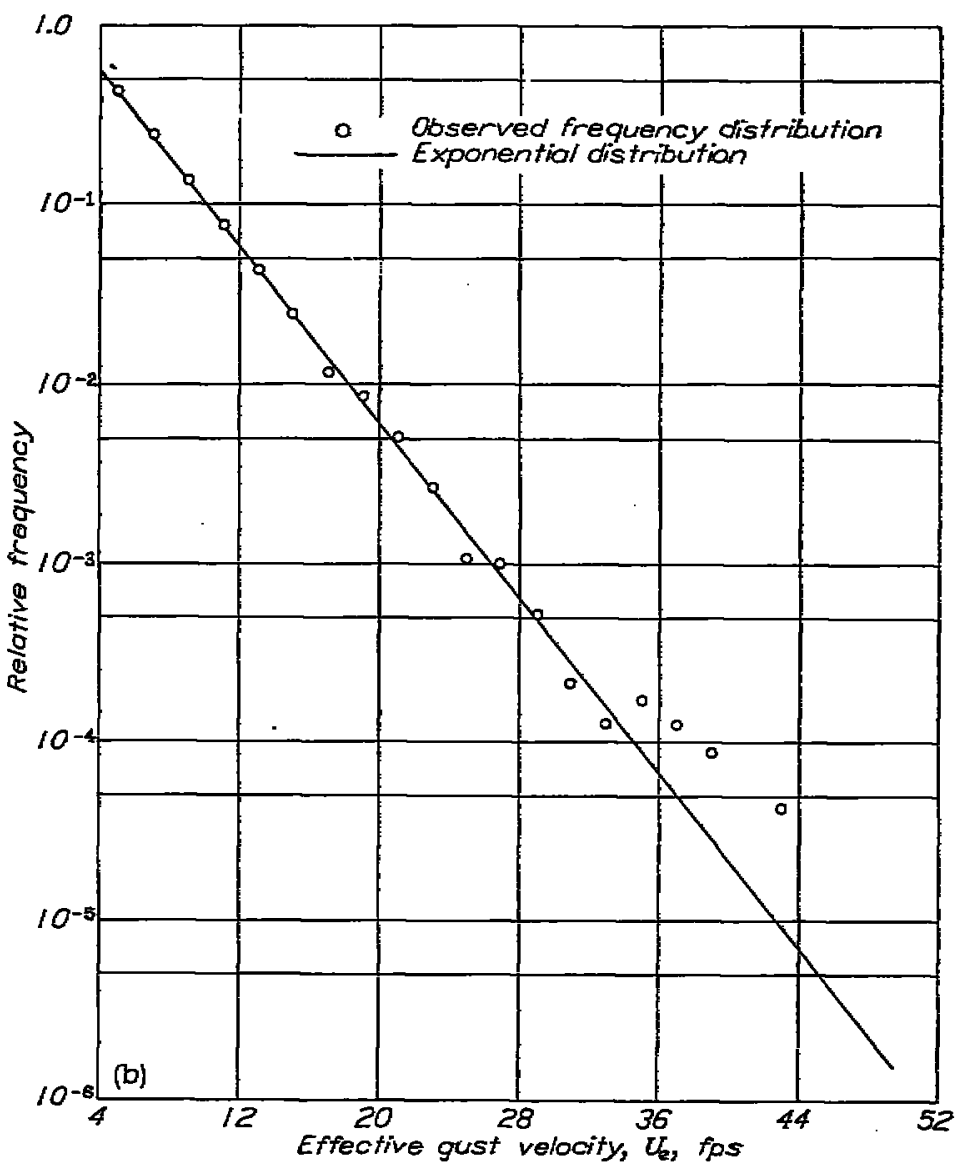

(b) 1917 Thunderstorm Project data. Total number of observations, 22,960. FIGURe 6.-Continued. 


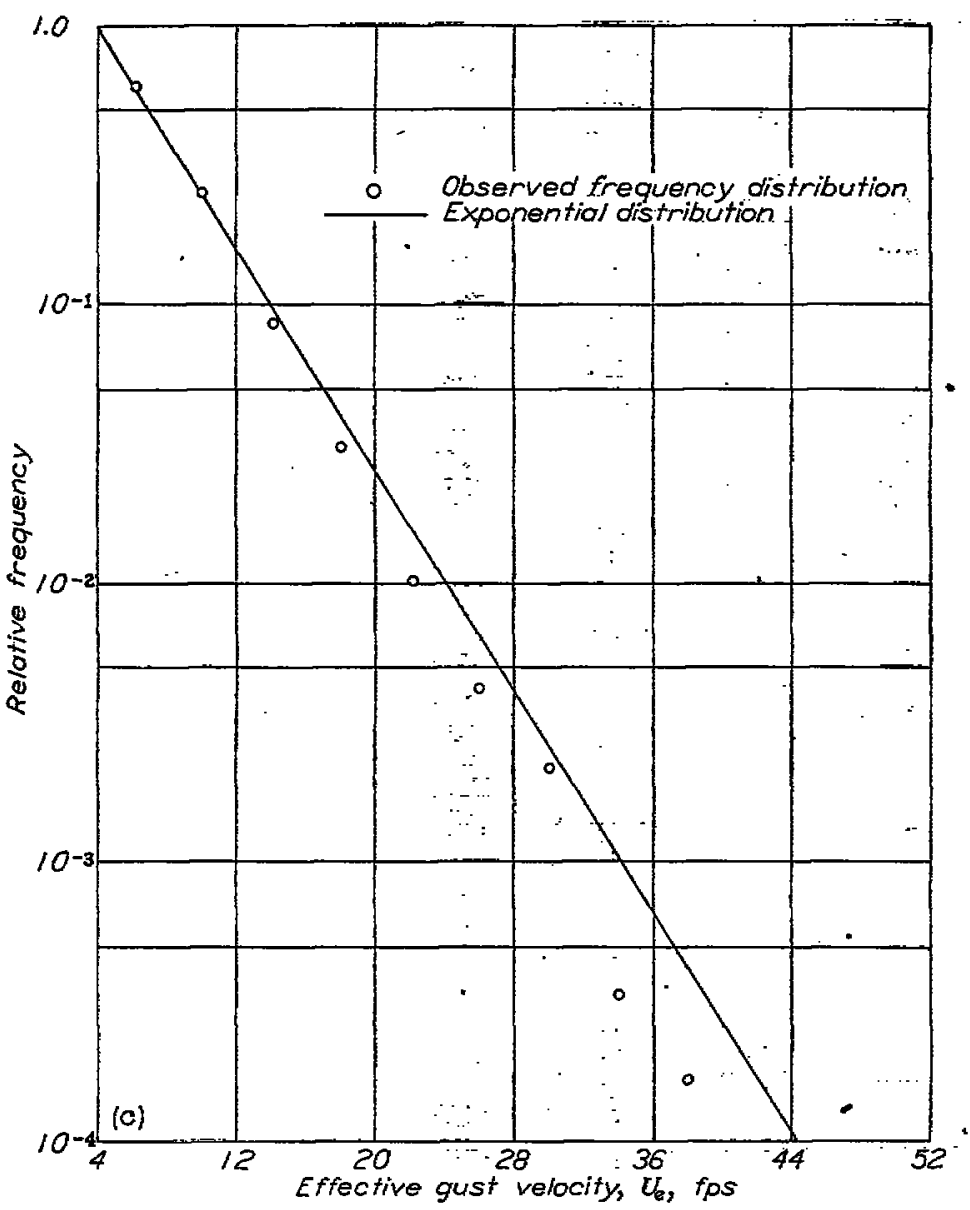

(c) Data from XC-35 airplane investigations during 1941 and 1042. Total number of observations, 6,032

Figune 6.-Concluded.

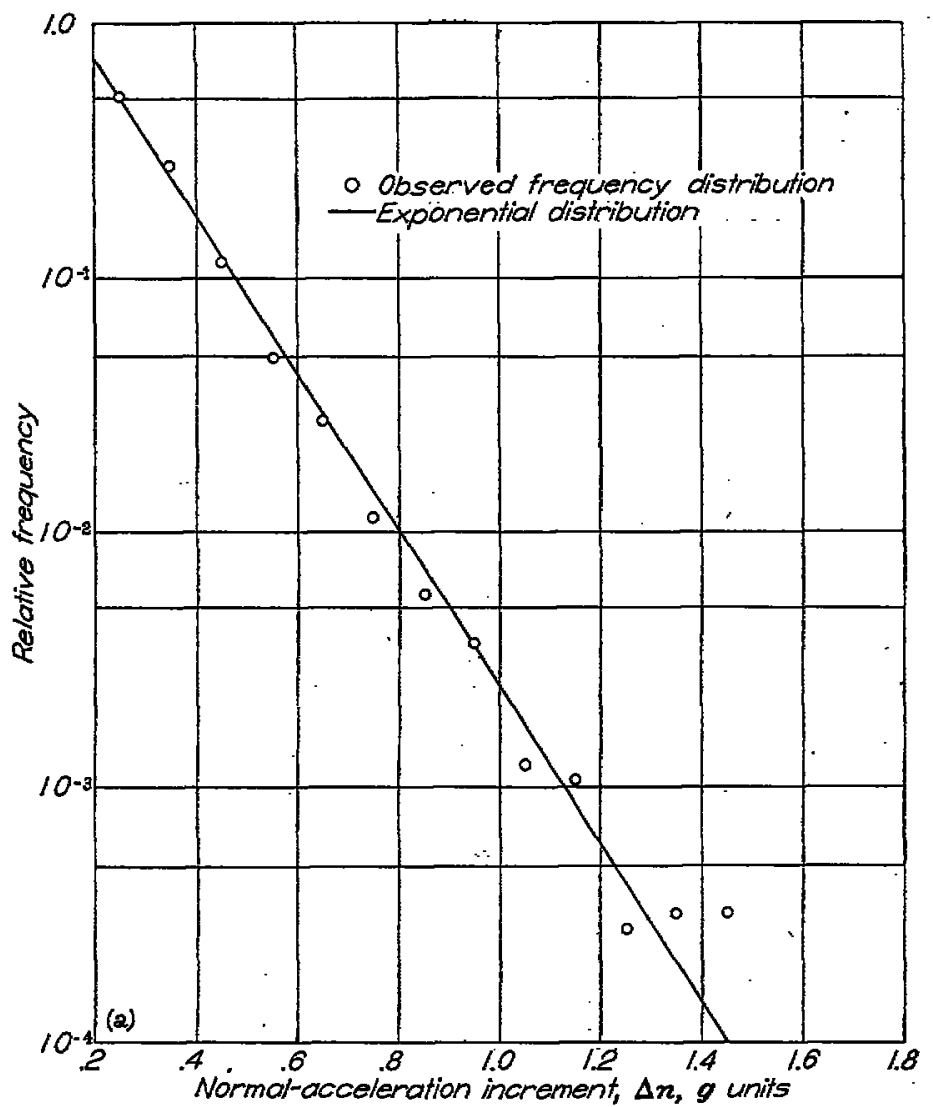

(a) 1946 Thunderstorm Project data. Total number of ubservations, 21,385. FiguRe 7.-Distribution of normaj-acceleration increment $\Delta \ddot{\Delta}$.

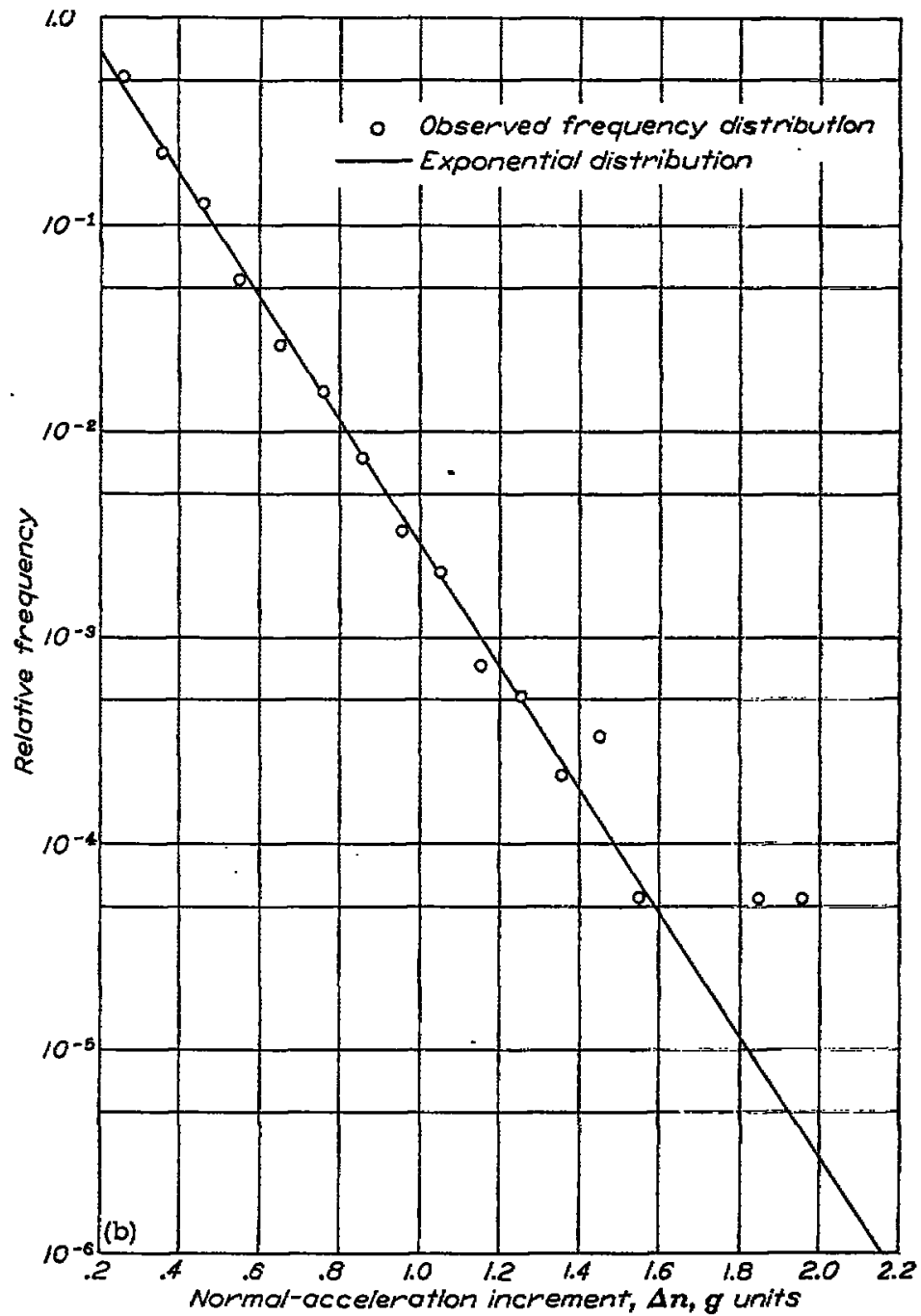

(b) 1947 Thunderstarm Project date. Total number of obscrvations, 17,307. FIOTRE 7.-Continued.

Figure 9 (a) presents the results obtained for the six sets of $\mathrm{V}-\mathrm{G}$ data. The straight line shown in the figure indientes equality between predicted and actual mileagr. For purposes of comparison, a similar plot is shown in figure 9 (b) for the same samples of data but with the predicted mileage values obtained by means of fitting Pearson type III probability curves to the distributions of maximum arccleration increments.

Figure 10 presents a comparison of the average life to limit load factor as obtained by using extreme-value and Pearson type III distributions for the six sets of data. Inasmuch as the estimates are generally extrapolations, a measure of the degree of extrapolation, the ratio of the maximum acceleration increment to the limit acceleration increment, is also given for each sample in the figure.

In addition to the application of the extreme-value distribution to distributions of maximum values of $\Delta n$ from $Y=\mathrm{G}$ records, some efforts have been made to apply this distribution to the observed distributions of maximum values of $U_{e}$ and $V_{\max }$ obtained from $V-G$ records. Although the results obtained appear indicative, they do not appear to warrant presentation in detail at this time. 


\section{DISCUSSION}

The foregoing results have indicated that the distribution of extreme values given by equation (7) is the limiting form for distributions of maximum values where the maximum values are selected from large samples from an initial distribution of the exponential type. Methods have been presented for the fitting of extreme-ralue distributions. The methods require the estimation of only the first two moments of the distribution and may be applied simply and rapidly. Methods have also been presented which allow the estimation of the relia-

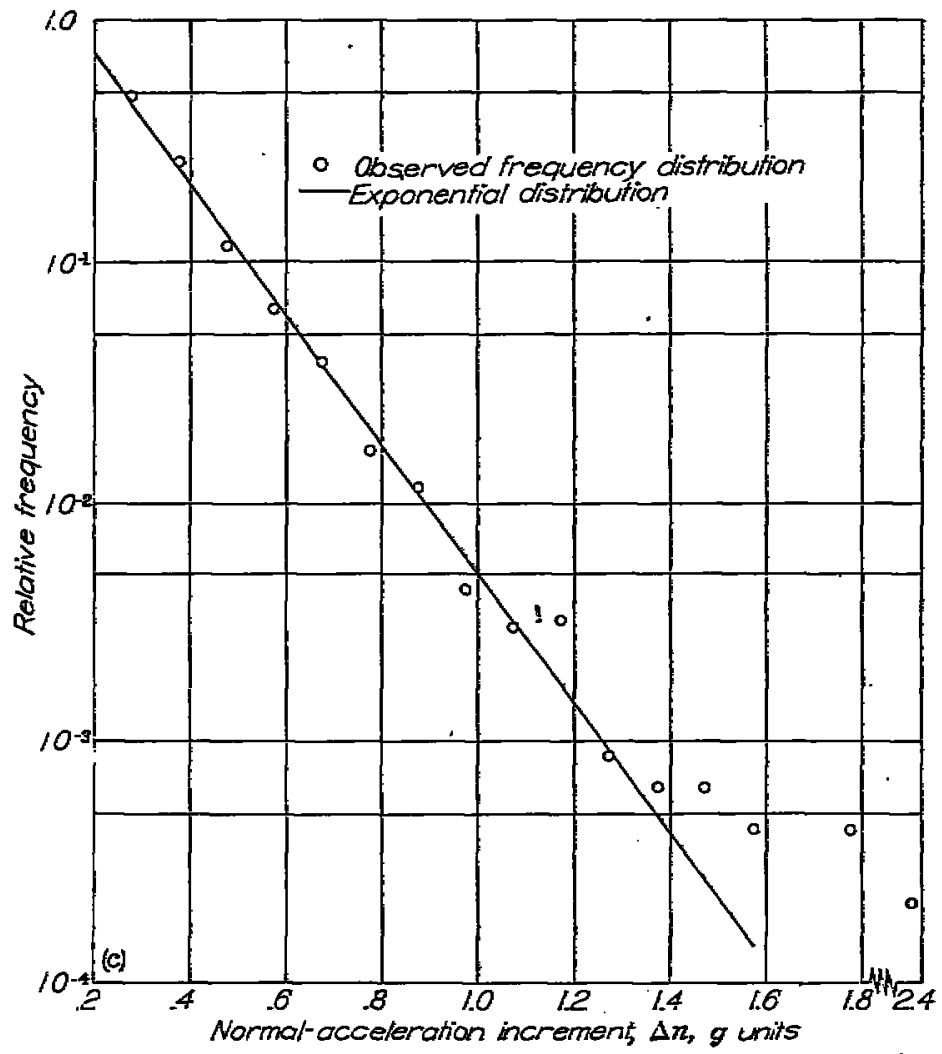

(c) Data from XC-35 airplane investigations during 1941 and 1942. Total number of observations, $4,5+5$.

Figtre 7.-Concluded. bility of the predicted probabilities of exceeding the extreme values. It would appear, therefore, that, if applicable, the use of distribution of extreme values for analysis of gust loads would offer significant advantages.

In order to determine whether the distribution of extreme values is applicable to gust-load variables, the available distributions have been examined. Distributions of $U_{c}$ are arailable for a wide rariety of test conditions covering turbulence within clear air, stratus clouds, cumulus clouds, thunderstorm clouds, and areas of radar echo. The arailable data, although admittedly limited, nevertheless indicate that for each of the test conditions the distribution of effectire gust velocity appears of the exponential type with variations in arerage spacing between gusts and rariations in the standard deriations for the different distributions. Consideration of the most extensive distributions of $U_{t}$ shown in figure 6 indicates that the exponential distributions shown by the fitted straight line are good representations of the data. Therefore, the distribution of extreme values would appear to apply to the effective gust relocity for given test conditions.

The arailable distributions of $\Delta n$ hare been obtained, largely, under test flight conditions in which the airspeeds have been kept constant or at least restricted. The linear relation betreen $\tau_{\text {s }}$ and $\Delta n$ in the sharp-edge gust relation would, consequently, be expected to yield the same form for the distribution of $U_{a}$ and $\Delta n$. The distributions of $\Delta n$ shown in figure 7 substantiate the expectation that the form of the distributions of $\Delta n$ is the same as the distributions of $L^{T}$ of figure 6. It may be concluded that for test flights at constant speed at least the distribution of $\Delta n$ would remain in the exponential form and the distribution of extreme values rould be applicable.

The arailable evidence as indicated by figure 8 appears to indicate that the distribution of $C_{t}$ also follows a simple exponential distribution. The distribution of extreme values may, therefore, also be applied to distributions of maximum values of $U_{t}$.

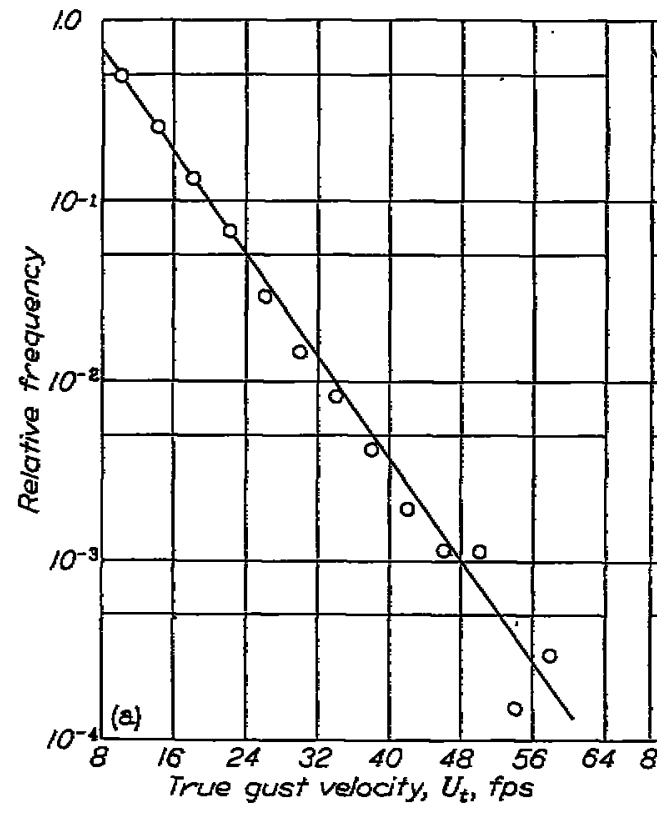

(a) 1946 Thunderstorm Project data. Total number of observitions, 6,715.

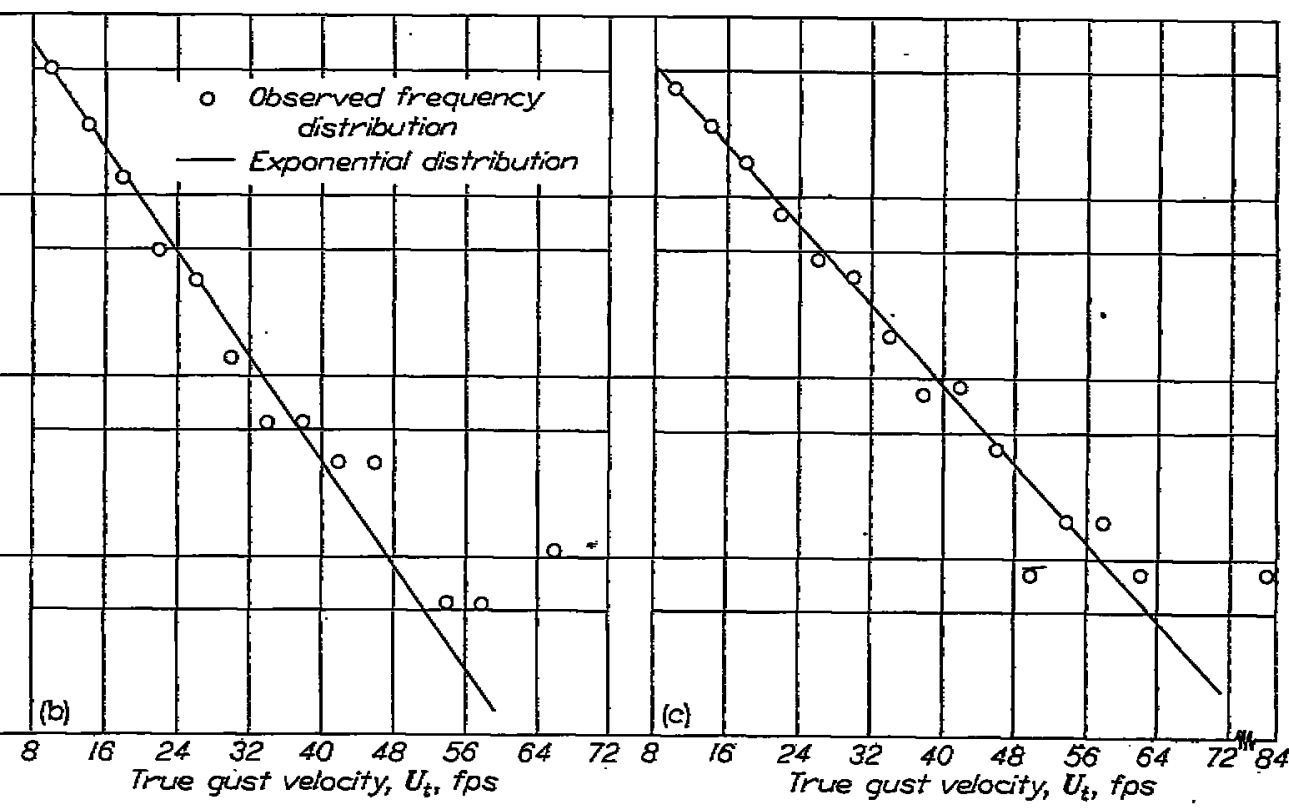

(b) 1947 Thunderstorm Project data. Total number of observations, 1,816 .

FinuRe 8.-Distribution of true gust rebeity $U_{f}$. (c) Data from XC-35 airplane in Festigatlons during 1341 and 1942. Total nimber of obser rations, 1,249 . 


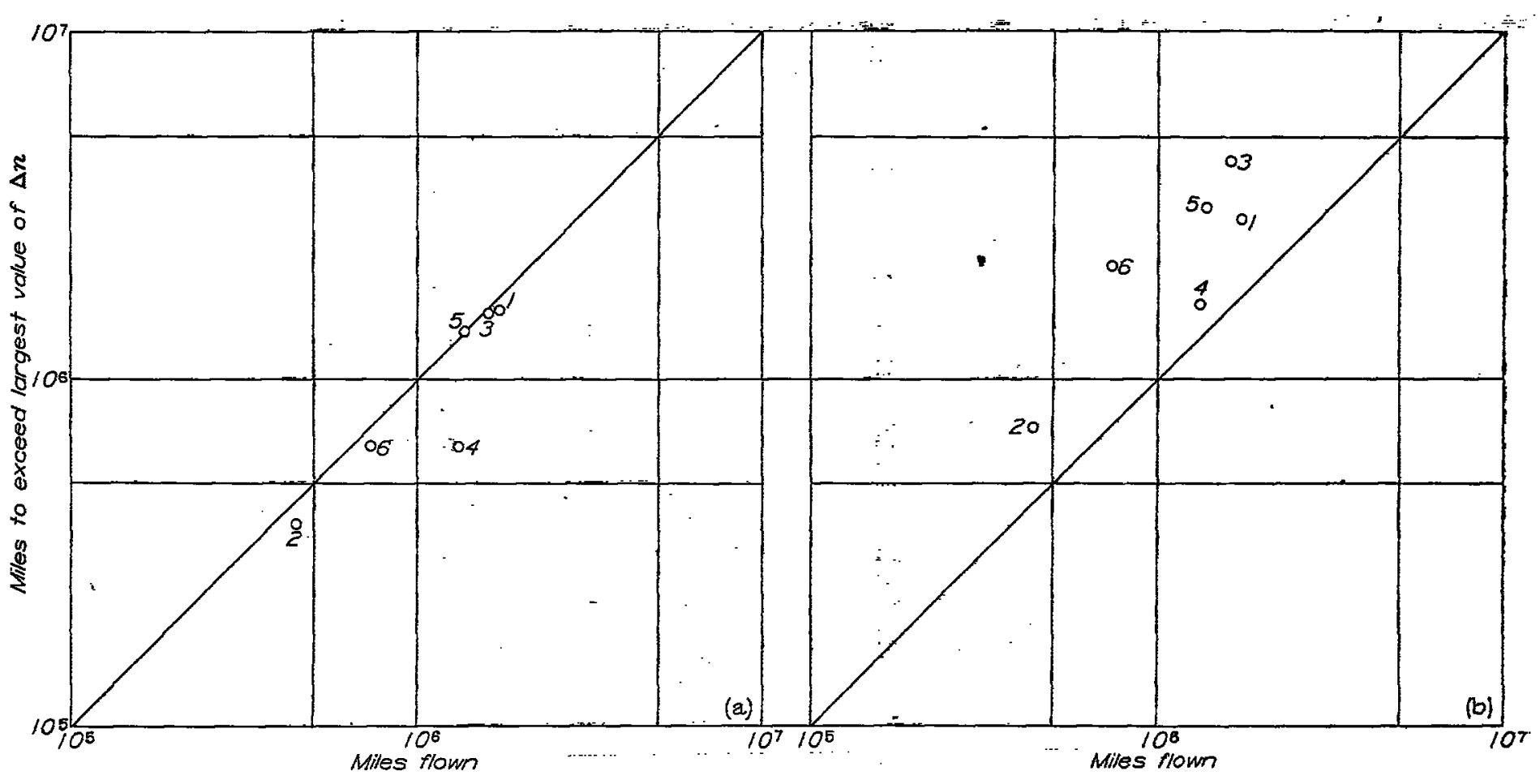

(a) Extreme values.

(b) Pearson type III.

Finvas 9.-Miles flown as a function of miles to exceed largest observed normal-acceleration increment for slx samples of $V$ - $Q$ recoris.

6

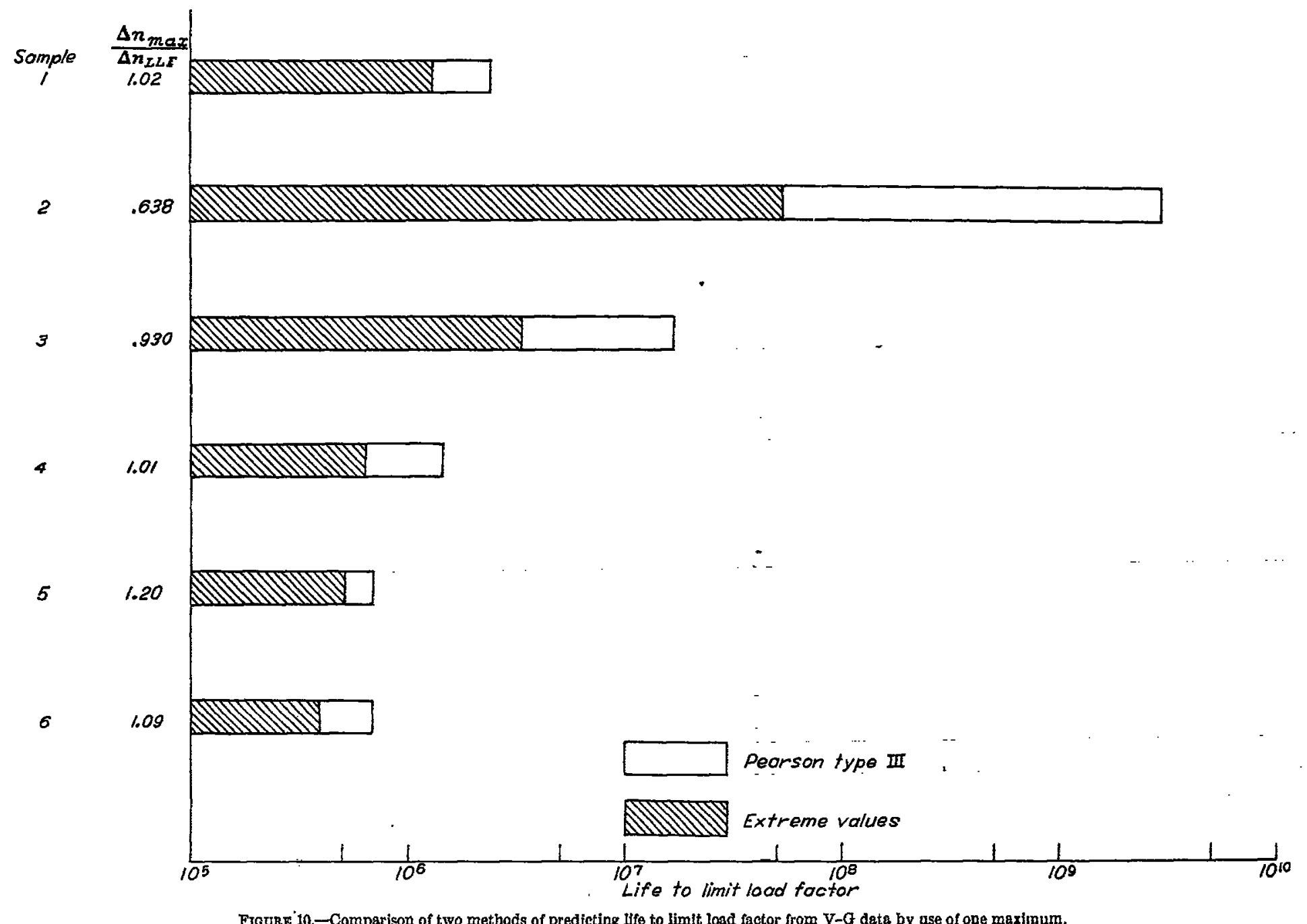

Finure 10,-Comparison of two metbods of predicting life to limit load factor from V-C data by use of one maximum. 
The question of the applicability of the extreme-value distribution to the maximum values of $U_{c}$ obtained from $V-G$ records from commercial operations arises since these records generally cover a wide variety of operating and weather conditions. Although the available data, in some cases, appear to indicate that the distributions of $U_{c}$ are of the exponential form, they do not extend to sufficiently high values to be conclusive. Arailable information on commercialtransport gust experience and on the frequency distributions of $U_{c}$ for various weather conditions indicates that the larger values encountered in commercial operations result largely from flight through thunderstorms and convective clouds. On the basis, then, that the distribution of gusts in conrective clouds is exponential, it seems reasonable to expect that the distribution of $U_{s}$ in commercial operations should have an exponential distribution at least for the larger values of gust velocity. Application of the distribution of extreme values would seem reasonable, therefore, to the distribution of maximum values of $U$, obtained from $V-G$ records.

In connection with the possible application of the distribution of extreme values to maximum values of acceleration increment obtained from $\Gamma-G$ records of commercial transport operations, the question of the airspeed operating practice may be of some importance. Apparently, a systematic rariation of airspeed as a function of gustiness could conceivably cause an appreciable departure from the exponential form in the distribution of $\Delta n$ even at the larger values. Little evidence is a railable, howerer, to indicate that such a systematic rariation exists in practice. On the assumption, then, that operating speeds in areas of moderate to severe turbulence are largely confined to a narrow speed range for a given airplane or are independent of the intensity of the turbulence, the application of the distribution to the maximum values of acceleration increment is reasonable.

Consideration has also been given to the applicability of the extreme-value distribution to maximum values of airspeed obtained from $V-G$ records. Little information is arailable, however, concerning the speed-time distribution of airspeed. Several attempts were made, consequently, to fit observed distributions by using the distribution of extreme values. The results have indicated that the observed distributions of $\Gamma_{\max }$ are frequently skewed negatively as compared with the positive skew of the distribution of extreme ralues. As a result, the agreement between the observed data and the distribution of extreme ralues was poor. The limited information available on the speed-time distribution of airspeed has further indicated that the distribution of airspeeds follows no simple exponential form and depends largely on operational practice. The distribution function of equation (7) would, therefore, appear not to be applicable to distributions of maximum values of airspeed.

Another variable frequently studied in gust-load investigations is the airspeed at which the maximum acceleration on a $V-G$ record is encountered. By definition, this variable does not represent maximum values of airspeed and, as a result, no initial distribution that is directly related to this variable is apparent. Available distributions of $T_{0}$ have been examined, however, and the results indicated that the distribution of extreme values of equation (7) is not applicable to distributions of these data.

It has been indicated that the distribution of extreme values of equation (7) is a rational distribution form for purposes of fitting distributions of maximum ralues of $\Delta n$, $U_{\epsilon}$, and $U_{t}$ when the maximums are selected from a large number of obserrations. The need remains for indicating that the application of this distribution yields accurate predictions. The rerification of statistical techniques of this type requires huge masses of data. Sufficient data are not available to enable a complete answer to this question. Arailable data may be used, howrever, to compare the estimates obtained with those obtained by the methods commonly used in the analysis of $T-G$ records.

The comparison shown in figure 9 (a) between the estimated miles to exceed the highest observed value of $\Delta n$ based on extreme-value methods and the actual miles flown indicates that the agreement is extremely good. In only one case is any appreciable difference noted and in this case the actual mileage is about twice the estimated mileage. The same comparison between the estimated miles to equal or exceed the maximum values obtained by Pearson type III curves and the actual miles flown is shown in figure 9 (b). The figure indicates appreciably more scatter with the predicted miles always greater than the actual miles with the ratio of the predicted to actual miles in two cases about 3 to 1 . This tendency toward orerestimation of miles to exceed given accelerationincrement ralues is unconservative and may be misleading. On this basis, the extreme-value distribution apparently yields more reliable estimates of the frequency of encountering the larger values.

Since the miles required to exceed limit load factor is of particular concern, the comparison shown in figure 10 of the estimates to exceed limit load by the extreme-ralue and Pearson type III curres becomes of interest. Consideration of figure 10 indicates that the Pearson curves in èvery case yield larger mileage estimates. The differences between the estimates at limit load factor rary appreciably as indicated by the ratio of the mileages which vary from about 1.3 to 60. Consideration of the ratios of the maximum values of $\Delta n$ observed to limit load factor for each set of data indicates that the magnitude of the differences between the results of the two methods increases with the degree of extrapolation required to reach limit load factor.

In summary, then, the foregoing comparisons have indicated that, as compared with previous methods of analysis, extreme-value methods yield results more consistent with the data at the largest values. The differences between the estimates are considerably amplified when comparisons are made at extrapolated portions of the distributions. In view of this evidence and the rational foundation for the extremevalue distribution presented previously, the use of this distribution would generally be expected to provide more reliable estimates. 
In the practical application of extreme-value methods to the analysis of $V_{-} G$ records, it should be noted that the extreme-value distribution of the maximum values of $\Delta n$ may be used, in conjunction with the methods of reference 1 , to predict the velocity-acceleration or $\mathrm{V}-\mathrm{N}$ envelope for a given airplane. It has also been suggested that the determination of the $\mathrm{V}-\mathrm{N}$ envelope should be made by analysis of the accelerations by speed bracket. In this connection, the use of extreme-value methods would also seem proper provided that for each record a large number of accelerations are experienced within each of the speed brackets chosen.

Another problem.encountered, in practice, is that estimates of the frequency distribution are frequently required for very limited samples, sometimes as few as ten records. In order to increase the sample size, the practice has been to use both the maximum positive and maximum negative acceleration increments from each record; the sample size is thereby doubled. Although this practice departs somewhat from the extreme-value theory, an analysis of available data indicated that the use of two maximums per record for the larger samples had only a minor effect on the estimates obtained. The use of two maximums per record would appear, therefore, to offer a useful basis for increasing sample size, particularly for very limited samples.

\section{CONCLUDING REMARKS}

An analysis of gust-load data by the use of the statistical theory of extreme values has indicated the following results:

1. The theory of extreme. values gives a rational form for the distribution of maximum values that appears applicable to distributions of maximum values of the effective gust velocity, true gust velocity, and normal-acceleration increment obtained from test flights or commercial transport operations.

2. Simple methods are arailable for fitting the distribution of extreme values to samples of data and for obtaining control curves that provide a measure of the reliability of the estimates of encountering the larger values. A simple and reasonable, but nonrigorous, method of determining whether differences betwreen two estimates may be considered significant is also presented.

3. The application of the distribution of maximum values to available V-G data yields estimates of the frequency of encountering the larger acceleration increments that are consistent with the available data and appear to be more reliable than the estimates abtained in previous analyses.
4. Notwithstanding the fact that the methods described in the present report appear to be applicable, the possibility must always be kept in mind that, because of limitations of the method, available records, or both, a value may occur that far exceeds the limits of the theoretical predictions.

Langlëy Aeronautical Laboratory,

National Advisori CoMmitee ror Aeronatutics, LANGLEY Field, VA., July 22, 1949.

\section{REFERENCES}

1. Peiser, A: M., and Wilkerson, M.: A Method of Analysis of $Y-G$ Records from Transport Operations. NACA Reps. 807, 1915.

2. Peiser, A. M., and Walker, W. G.: An Analysis of the Airepects and Normal Accelerations of Boeing S-307 Airplanes in Commercial Transport Operation. NACA TN 1141, 10.46.

3. Peiser, A. M.: An Analysis of the Airspeeds and Normal Accelerations of Douglas DC-3 Aiplanes in Commerelal Transyort Operation. NACA TN $1142,1946$.

4. Fisher, R. A., and Tippeti, L. H. C.: Limiting Forms of the Frequency of the Largest or Sinallest Member of a Sample. Pruc. Cambridge Phil. Soc., vol. 24, pt. 2, 1927-1928, pp. 180100.

5. Gumbel, E. J.: Les Valeurs Extrêmes des Distributions Statistiques. Ann. de L'Institut Henri Poincare, vol. 5, pt. 2, 1935, pp. 115-158.

6. Gumbel, E. J.: The Return Period of Flood Flows. The Annals of Mathematical Statistics, vol. XII, no. 2, June 19.11, [pp. 103-100.

7. Gumbel, E. J.: Simplified Plotting of Statistical Oleservations. Trans., Am. Geophys. Union, vol. 26, pt. I, Aug. 19.45, 1pp. 69.82.

8. Gumbel, E. J.: Statistical Control Curves fur Flood-Discharges. Trans., Am. Geophys. Union, April 3, 1042, pp. 480-500.

9. Gumbel, E. J.: The Statistical Forecast of Floods. The Graduate Faculty of Political and Social Science, The New School for Social Research, New York, Dec. 1948.

10. Kimball, Bradford F.: Sufficient Statistical Estimation Functions for the Parameters of the Distribution of Maximum Valucs. The Annals of Mathematical Statistios, vol. XVII, no. 3, Sept 1946, pp. 299-309.

11. Kendall, Maurice G.: The Advanced Theory of Statlstics. Vol. II; second ed., Charies Griffin and Co., Ltd. (London), 1048, ch. 20, pp. 85-95.

12. Rhode, Richard $V$., and Donely, Philip: Frequency of Occurrence of Atmospheric Gusts and of Related Loads on Airpiano Structures. NACA ARR L4I21, 1044.

13. Tolefson, Harold B.: Preliminary Analysis of NACA Mcasurements of Atmospheric Turbulence within a ThunderstormU. S. Weather Bureau Thunderstorm Project. NACA TN $123 \overline{3}, 1947$.

14. Tolefson, H. B.: An Analysis of the Variation with Altitude of Effective Gust Volocity in Convective-Type Clouds. NACA TN 1628, 1948. 
TABLE I.CUMULATIVE PROBABILITY DISTRIBUTION $F *(y)=1-e^{-e^{-y \dagger}}$

\begin{tabular}{|c|c|c|c|c|c|c|c|}
\hline$y$ & $F^{*}(y)$ & $y$ & $F^{*}(y)$ & 7 & $F^{*}(\boldsymbol{V})$ & $y$ & $F^{*}(y)$ \\
\hline $\begin{array}{r}-2.50 \\
-2.45 \\
-2.10 \\
-2.35 \\
-2.30 \\
-2.25 \\
-2.20 \\
-2.15 \\
-2.10 \\
-2.05 \\
-2.00 \\
-1.95 \\
-1.90 \\
-1.85 \\
-1.80 \\
-1.75 \\
-1.70 \\
-1.65 \\
-1.60 \\
-1.55 \\
-1.50 \\
-1.45 \\
-1.40 \\
-1.35 \\
-1.30 \\
-1.25 \\
-1.20 \\
-1.15 \\
-1.10 \\
-1.05 \\
-1.00 \\
-.95 \\
-. .90 \\
-.85 \\
-.80 \\
-.75 \\
-.70 \\
-.65 \\
-.60 \\
-.55 \\
-.50 \\
-.45 \\
-.40 \\
-.35 \\
-.30 \\
-.25 \\
-.20 \\
-.15 \\
-.10 \\
-.05 \\
0 \\
-05 \\
.10\end{array}$ & 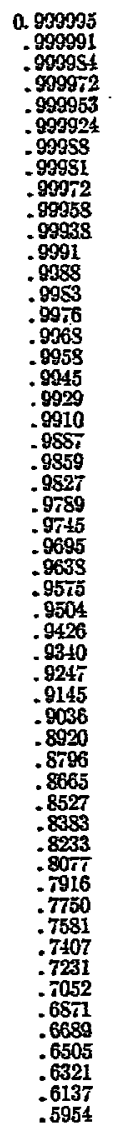 & $\begin{array}{l}0.15 \\
-20 \\
-25 \\
.30 \\
-35 \\
.40 \\
.45 \\
.50 \\
-55 \\
.60 \\
-65 \\
.70 \\
-75 \\
.80 \\
.85 \\
.90 \\
.95 \\
1.00 \\
1.05 \\
1.10 \\
1.15 \\
1.20 \\
1.25 \\
1.30 \\
1.35 \\
1.40 \\
1.45 \\
1.50 \\
1.55 \\
1.60 \\
1.65 \\
1.70 \\
1.75 \\
1.80 \\
1.85 \\
1.90 \\
1.95 \\
2.00 \\
205 \\
210 \\
2.15 \\
2.20 \\
2.25 \\
2.30 \\
235 \\
2.40 \\
2.45 \\
2.50 \\
2.55 \\
2.60 \\
2.65 \\
270 \\
2.75\end{array}$ & 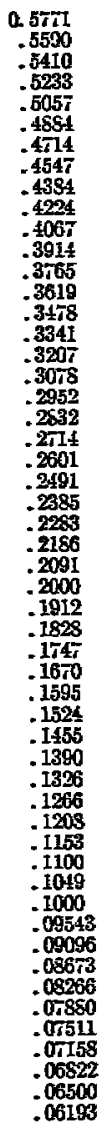 & $\begin{array}{l}2.80 \\
2.85 \\
2.90 \\
2.95 \\
3.00 \\
3.05 \\
3.10 \\
3.15 \\
3.20 \\
3.25 \\
3.30 \\
3.35 \\
3.40 \\
3.45 \\
3.50 \\
3.55 \\
3.60 \\
3.65 \\
3.70 \\
3.75 \\
3.80 \\
3.85 \\
3.90 \\
3.95 \\
4.00 \\
4.05 \\
4.10 \\
4.15 \\
4.20 \\
4.25 \\
4.30 \\
4.35 \\
4.40 \\
4.45 \\
4.50 \\
4.55 \\
4.60 \\
4.65 \\
4.70 \\
4.75 \\
4.80 \\
4.85 \\
4.90 \\
4.95 \\
5.00 \\
5.05 \\
5.10 \\
5.15 \\
5.20 \\
5.25 \\
5.30 \\
5.35 \\
5.40\end{array}$ & 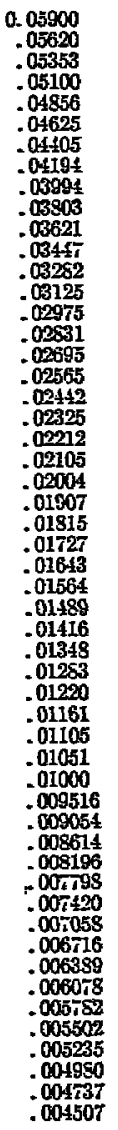 & $\begin{array}{l}5.45 \\
5.50 \\
5.55 \\
5.60 \\
5.65 \\
5.70 \\
5.75 \\
5.80 \\
5.85 \\
5.90 \\
5.95 \\
6.00 \\
6.05 \\
6.10 \\
6.15 \\
6.20 \\
6.25 \\
6.30 \\
6.35 \\
6.40 \\
6.45 \\
6.50 \\
6.55 \\
6.60 \\
6.65 \\
6.70 \\
6.75 \\
6.80 \\
6.85 \\
6.90 \\
6.95 \\
7.00 \\
7.05 \\
7.10 \\
7.15 \\
7.20 \\
7.25 \\
7.30 \\
7.35 \\
7.40 \\
7.45 \\
7.50 \\
7.55 \\
7.60 \\
7.65 \\
7.70 \\
7.75 \\
7.80 \\
7.85 \\
7.30 \\
7.95 \\
8.00\end{array}$ & 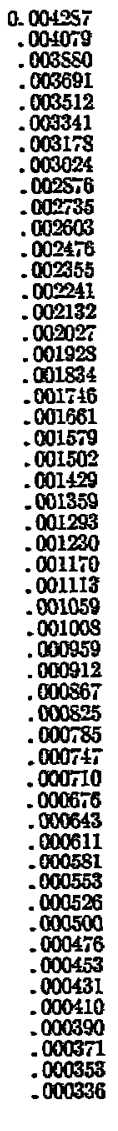 \\
\hline
\end{tabular}

tTable ralues are sccurate to \pm 1 in last decimal place. 
TABLE II

SUMMARY OF CALCULATIONS, 1946 U. S. WEATHER BUREAU THUNDERSTORM PROJECT DATA

[Example 1]

\begin{tabular}{|c|c|c|c|c|c|c|}
\hline $\begin{array}{c}U_{e} \\
\text { (pss) }\end{array}$ & Midpoint, & Frequency, & $\begin{array}{l}\text { Cumulativa } \\
\text { frequeney, } \\
F\end{array}$ & $\begin{array}{c}\text { Relative } \\
\text { cumiulative } \\
\text { frequency, } F / N\end{array}$ & $\sigma_{a} f$ & $U_{e}^{2 f}$ \\
\hline 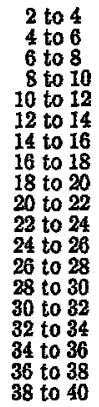 & $\begin{array}{c}\mathbf{3} \\
5 \\
7 \\
9 \\
11 \\
13 \\
15 \\
11 \\
119 \\
21 \\
23 \\
225 \\
27 \\
29 \\
31 \\
33 \\
35 \\
37 \\
39\end{array}$ & $\begin{array}{c}41 \\
11 \\
27 \\
48 \\
62 \\
58 \\
55 \\
60 \\
61 \\
36 \\
17 \\
18 \\
8 \\
7 \\
6 \\
3 \\
1 \\
2 \\
1\end{array}$ & 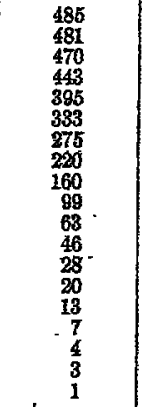 & 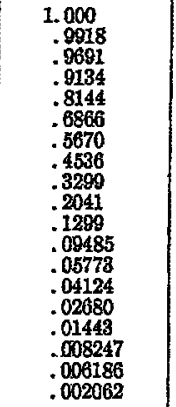 & 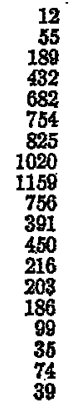 & 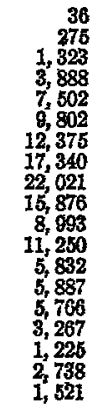 \\
\hline$\Sigma$ & & 485 & $\because$ & & 7577 & 136,917 \\
\hline
\end{tabular}

\begin{tabular}{|c|c|c|}
\hline$\underset{\text { (fps) }}{\tau_{s}}$ & $y$ & $F^{*}(y)$ \\
\hline $\begin{array}{c}2 \\
4 \\
6 \\
8 \\
10 \\
12 \\
14 \\
16 \\
18 \\
20 \\
22 \\
24 \\
26 \\
28 \\
30 \\
32 \\
34 \\
36 \\
38 \\
40 \\
42 \\
44 \\
46 \\
48\end{array}$ & 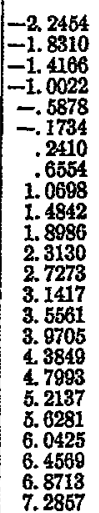 & 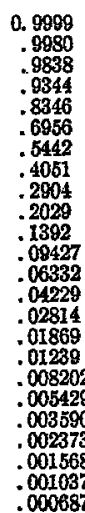 \\
\hline
\end{tabular}

Derivation of transformation equation:

$\bar{U}_{.}=15.6227$

$\frac{1}{\alpha}=4.8263$

$s_{U_{e}}=6.1899$

$u=12.8370$

$y=\frac{U_{s}-12.8370}{4.8263}$

TABLE III

CALCULATIONS FOR THE DETERMINATION OF THE CONTROL INTERVALS

[Example 1: $\left.\frac{1}{\alpha}=4.8263\right]$

\begin{tabular}{|l|c|c|}
\hline \multirow{2}{*}{$F^{*}\left(U_{c}\right)$} & \multicolumn{2}{|c|}{ Control interval } \\
\cline { 2 - 3 } & 68 percent & 85 percent \\
\hline$\frac{1}{485}=0.002062$ & $(4.8263)(1.14)=5.5020$ & $(4.8263)(2.07)=14.3341$ \\
$\frac{2}{485}-0.004124$ & $\frac{(4.8268)(0.75)(485)}{483}-3.6347$ & $\frac{(4.8263)(1.73)(485)}{483}=8.3841$ \\
0.10 & $\frac{(3.16)(4.8263)}{\sqrt{485}}=0.6825$ & $\frac{(6.32)(4.8263)}{\sqrt{485}}=1.3850$ \\
0.25 & $\frac{(2.00)(4.8263)}{\sqrt{485}}=0.43 \$ 3$ & $\frac{(4.00)(4.8263)}{\sqrt{485}}=0.8766$ \\
0.50 & $\frac{(1.44)(4.8263)}{\sqrt{485}}=0.3156$ & $\frac{(2.88)(4.8263)}{\sqrt{485}}=0.8312$ \\
\hline
\end{tabular}

TABLE IV

SUMMARY OF CALCULATIONS, V-G DATA

[Example 2]

\begin{tabular}{|c|c|c|c|c|c|}
\hline (o units) & $\begin{array}{c}\text { Serial } \\
\text { number, } \\
m\end{array}$ & $\frac{n-m+1}{n}$ & $y$ & $y^{2}$ & $\Delta n^{8}$ \\
\hline $\begin{array}{l}0.50 \\
.61 \\
.85 \\
.66 \\
.70 \\
.73 \\
.80 \\
.80 \\
.82 \\
.91 \\
-.91 \\
.98 \\
.90 \\
.1 .00 \\
1.00 \\
1.05 \\
1.05 \\
1.10 \\
1.20 \\
1.25 \\
1.30 \\
1.30 \\
1.35 \\
1.40 \\
1.65 \\
1.80\end{array}$ & $\begin{array}{r}1 \\
2 \\
3 \\
4 \\
4 \\
5 \\
6 \\
7 \\
8 \\
9 \\
10 \\
11 \\
12 \\
13 \\
14 \\
15 \\
16 \\
17 \\
18 \\
19 \\
20 \\
21 \\
22 \\
28 \\
24 \\
25 \\
26\end{array}$ & 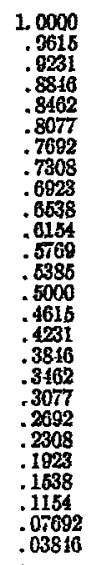 & $\begin{array}{r}=1.182 \\
=.942 \\
=.770 \\
-.627 \\
=.500 \\
=.383 \\
=.272 \\
=.164 \\
-.059 \\
.045 \\
.161 \\
.257 \\
.356 \\
.490 \\
.098 \\
.7283 \\
.856 \\
1.000 \\
1.100 \\
1.338 \\
1.444 \\
1.790 \\
2.099 \\
2.525 \\
3.239\end{array}$ & 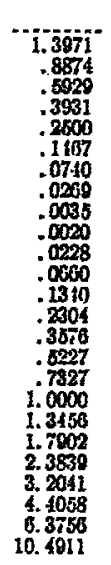 & 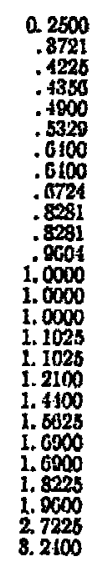 \\
\hline 20. 52 & & & 13.272 & 30.8361 & 29.0116 \\
\hline
\end{tabular}

\begin{tabular}{|c|c|c|}
\hline (o units) & $y$ & $F^{*}(v)$ \\
\hline $\begin{array}{r}0.50 \\
.60 \\
.70 \\
.80 \\
.90 \\
1.00 \\
1.10 \\
1.20 \\
1.30 \\
1.40 \\
1.50 \\
1.60 \\
1.70 \\
1.80 \\
1.90 \\
2.00 \\
2.10 \\
2.20\end{array}$ & $\begin{array}{r}-1.2784 \\
-. .9304 \\
-. .8525 \\
-.2345 \\
.1134 \\
.4614 \\
. .8093 \\
1.1573 \\
1.50552 \\
1.8552 \\
2.2011 \\
2.6491 \\
2.8970 \\
3.2450 \\
3.5529 \\
3.9408 \\
4.2888 \\
4.6367\end{array}$ & 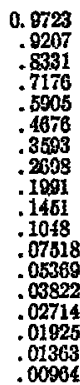 \\
\hline
\end{tabular}

Derivation of transformation equation:

$\overline{\Delta n}=1.0200$

$s \Delta n=0.3202$

$\frac{1}{\alpha}=0.2874$

$\bar{y}=0.5309$

$s_{y}=1.1141$

$u=0.8074$

$y=\frac{\Delta n-0.8674}{0.2874}$

TABLE V

CALCULATIONS FOR THE DETERMINATION OF THE CONTROL INTERVALS

[Example 2; $\left.\frac{1}{\alpha}=0.2874\right]$

\begin{tabular}{|c|c|c|}
\hline \multirow{2}{*}{$F^{* *}(\Delta n)$} & \multicolumn{2}{|c|}{ Control interval } \\
\hline & 68 percent & 95 percent \\
\hline$\frac{1}{26}=0.0335$ & $(0.2874)(1.14)=0.328$ & $(0.2874)(2.07)=0.854$ \\
\hline$\frac{2}{26}=0.0760$ & $\frac{(0.2874)(0.75)(26)}{24}-0.234$ & $\frac{(0.2574)(1.73)(20)}{24}=0.639$ \\
\hline 0.10 & $\frac{(3.16)(0.2874)}{\sqrt{26}}=0.178$ & $\frac{(6.32)(0.2874)}{\sqrt{26}}-0.350$ \\
\hline 0.25 & $\frac{(2.00)(0.2874)}{\sqrt{28}}=0.113$ & $\frac{(4.00)(0.2874)}{\sqrt{26}}-0.225$ \\
\hline 0.50 & $\frac{(1.44)(0.2874)}{\sqrt{26}}=0.0812$ & $\frac{(2.88)(0.2879)}{\sqrt{28}}=0.162$ \\
\hline
\end{tabular}

